\title{
Physical self-efficacy in women's artistic gymnastic between recreational and competitive level
}

\author{
FILIPPO GOMEZ PALOMA , LAURA RIO, CRISTIANA D'ANNA \\ Department of Physical Education and Sport, Faculty of Education, Catholic University. \\ Slovakia.
}

\begin{abstract}
Gomez-Paloma, F., Rio, L. \& D'Anna, C. (2014). Physical self-efficacy in women's artistic gymnastic between recreational and competitive level. J. Hum. Sport Exerc, 9(Proc1), pp.S341-S347. In Bandura's theory (1997, 2001), self-efficacy is the cognitive mechanism that mediates information on personal capacities to successfully execute necessary courses of action in a specific domain. It is theorized that self-efficacy belief influences motivation, affect and behaviour. Self-efficacy regarding motor activities has been widely investigated (Feltz, 1992) and represents a frame of reference to explain links between cognitive processes and physical performance (Colella \& Morano, 2008). The purpose of the study was to verify the difference in physical self-efficacy (perceived) between gymnasts practicing sports at recreational level and gymnasts, however, which train at a competitive level. The Perceived Physical Ability Scale for Children by Colella (2008) was presented to a sample of 58 gymnasts, 29 practicing sports at recreational level and 29 practicing sports at competitive level in random selection, ranging in age from 8 to 10 years old. The items of the PPASC are: speed, ability, strength, rapidity, self-confidence and tiredness. They are structured in response scales having a 1- to 4-point format. Observing the results of the descriptive statistics in the whole sample it is obvious how the perceived physical abilities are very high in all items. The artistic gymnastic is a sport in which these aspects of physical abilities are trained specifically. The children say that they run fast (77 \%), they are able to do difficult exercises $(77 \%)$, their muscles are strong $(68 \%)$ and move rapidly $(71 \%)$. Slightly lower values are those related to self-confidence, the $48 \%$ say that they feel sure when they move but the $32 \%$ say that they feel somewhat insure when they move, and the value of energy, $50 \%$ say I don't feel tired when I move, but the $25 \%$ say that they feel tired. The difference between the values of the two levels of gymnastic report in the competitive groups is higher in physical self-efficacy in all items than in the recreational group. These data could suggest that the quantity of the trainings and, at the same time, the improvement of the quality of the performance increases the Perceived Physical Ability. The results of the test is particularly high and considering it globally, confirms that, in any case, the physical activities, even if only practiced as recreational activity, produces positive effects on the Perceived Physical Ability. Key words: PHYSICAL SELF-EFFICACY, WOMEN'S ARTISTIC GYMNASTIC, STRENGTH, SPEED, CHILDREN.
\end{abstract}

Corresponding author. Department of Human, Philosophical and Educational Science, Education Science. University of Salerno, Salerno, Italy.

E-mail: fgomezpaloma@gmail.com

8th INSHS International Christmas Sport Scientific Conference, 5-7 December 2013. International Network of Sport and Health Science. Szombathely, Hungary.

JOURNAL OF HUMAN SPORT \& EXERCISE ISSN 1988-5202

(c) Faculty of Education. University of Alicante

doi:10.14198/jhse.2014.9.Proc1.18 


\section{INTRODUCTION}

The success in sport competitions, as just stressed by Bandura (2000), is obtained by some abilities not only physical. The cognitive factors, have a fundamental functioning of both the development and the motor learning. Be resolute, work regularly and constantly, facing the difficulties and obstacles be determined, are basic aspects to the agonistic activity in all sporting activities. Without doubt the choice of a competitive level is mainly conditioned by the psycho-physical conditions of the athlete and by his personal motivation towards that sport, but it strongly influences on the performance and on the competitive results the sense of the perceived efficacy.

In Bandura's theory $(1997,2001)$, self-efficacy is the cognitive mechanism that mediates information on personal capacities to successfully execute necessary courses of action in a specific domain.

The self-efficacy is a particular function that changes on the strength of situation and influences the cognitive processes and the level and persistence of motivation and affective states. According to this theory the perceived self-efficacy is strongly linked to motivation, affect and behaviour. If the athlete is certain to be able to obtain his aims with sacrifice and work, he will certainly have a greater motivation to train to reach the goals.

Self-efficacy regarding motor activities has been widely investigated. Feltz (1983) has shown that it is mainly the recent experiences that influence the perception of effectiveness that the athlete perceives before the competition. Interesting studies have shown that there is a close relationship between physical activity and academic outcomes (Multon et al., 1991) and connection between cognitive processes and performance (Feltz, 1992).

Other studies have demonstrated that exists a circular relation between self-efficacy and physical activity in which the first represents the factor that support the adhesion and the persistence to achieve the goal and the physical activity promote the perceived self-efficacy. In particular some researches have highlighted that in the meantime self-efficacy is both important and determinant, and a consequence of physical activity (McAuley \& Blissmer, 2002).

The purpose of this study is to verify the difference in physical self-efficacy (perceived) between children practicing sports at recreational level and children, however, which train at a competitive level in the women artistic gymnastic.

The gymnastic is an individual sport in which the perceived self-efficacy plays an essential role to the acquisition of specific abilities that often require a strong motivation, courage and determination.

\section{METHODS}

\section{Participants}

The sample is composed by 58 random children, aged from 8 to 10 years, all female.

They play artistic gymnastic and are members of Italian Gymnastic Federation (FGI).

One group $(n=29)$ practices gymnastic at competitive level from three years and the other group $(n=29)$ practices the same sport, but at recreational level from one or two years. 
The competitive group trains four days a week for two hours, whereas the recreational group trains only two day a week for one hour. The motor activities lessons are managed by gymnastic trainer selected by FGI in the both group.

Parents have been informed about this initiative through a written communication. They have signed the consent form for the use of personal data in accordance with the privacy policy.

\section{Procedure}

The test have been carried out in the last phase of competitive period, in which the competitive group is training the most important competition and the recreational group is preparing the final exhibition of the sport year.

The tool used to analyse the Perceived Physical Ability is PPASC test (Colella, 2008). It is a simply questionnaire structured in response scales having a 1- to 4-point format on the six items: speed, ability, strength, rapidity, self-confidence and tiredness (Table 1).

A label is assigned to each point of the response scales to help children grasp the meaning of the items. The scores of the first item, for example, range from 1 (I run very slowly) to 4 (I run very fast). Children are required to think of themselves when playing, performing physical education exercises, or when involved in sporting activities. For each item, participants are asked to choose one of the four sentences best representing their personal feelings. Items 1,3 , and 5 are scored 1 to 4 , whereas scores of items 2 , 4, and 6 are reversed.

High scores would indicate a high self-perception of physical ability, whereas low scores would reflect a low self-perception (Colella \& Morano, 2008).

Table 1. Items of the Perceived Physical Ability Scale for Children (Colella \& Morano, 2008)

\begin{tabular}{|c|c|c|c|c|}
\hline 1 & I run very slowly & I run slowly & I run fast & I run very fast \\
\hline 2 & $\begin{array}{l}\text { I am able to do very } \\
\text { difficult exercises }\end{array}$ & $\begin{array}{l}\text { I am able to do } \\
\text { difficult exercises }\end{array}$ & $\begin{array}{l}\text { I am able to do only } \\
\text { easy exercises }\end{array}$ & $\begin{array}{l}\text { I am able to do } \\
\text { only very easy } \\
\text { exercises }\end{array}$ \\
\hline 3 & $\begin{array}{l}\text { My muscles are very } \\
\text { weak }\end{array}$ & $\begin{array}{l}\text { My muscles are } \\
\text { weak }\end{array}$ & $\begin{array}{l}\text { My muscles are } \\
\text { strong }\end{array}$ & $\begin{array}{l}\text { My muscles } \\
\text { very strong }\end{array}$ \\
\hline 4 & I move very rapidly & I move rapidly & I move slowly & I move very slowly \\
\hline 5 & $\begin{array}{l}\text { I feel very insecure } \\
\text { when I move }\end{array}$ & $\begin{array}{l}\text { I feel somewhat } \\
\text { insecure when I } \\
\text { move }\end{array}$ & $\begin{array}{l}\text { I feel sure when I } \\
\text { move }\end{array}$ & $\begin{array}{l}\text { I feel very sure } \\
\text { when I move }\end{array}$ \\
\hline 6 & $\begin{array}{l}\text { I don't feel tired at all } \\
\text { when I move }\end{array}$ & $\begin{array}{l}\text { I don't feel tired } \\
\text { when I move }\end{array}$ & $\begin{array}{l}\text { I feel tired when I } \\
\text { move }\end{array}$ & $\begin{array}{l}\text { I feel very tired } \\
\text { when I move }\end{array}$ \\
\hline
\end{tabular}




\section{RESULTS}

Data collection, treatment, and analysis were per- formed using Microsoft Office Access and Excel 2010. Data for the whole sample were initially screened to determine the accuracy of data entry and to ascertain whether the assumption of normality of the distribution was met.

Descriptive statistics of the items and total score are reported in following figures.

In the fig. 1 and fig. 2 are highlighted the results in the separated groups: recreational level and competitive level; the fig. $3,4,5,6,7,8$ show the percentage value in the different items in the whole group by pie chart.

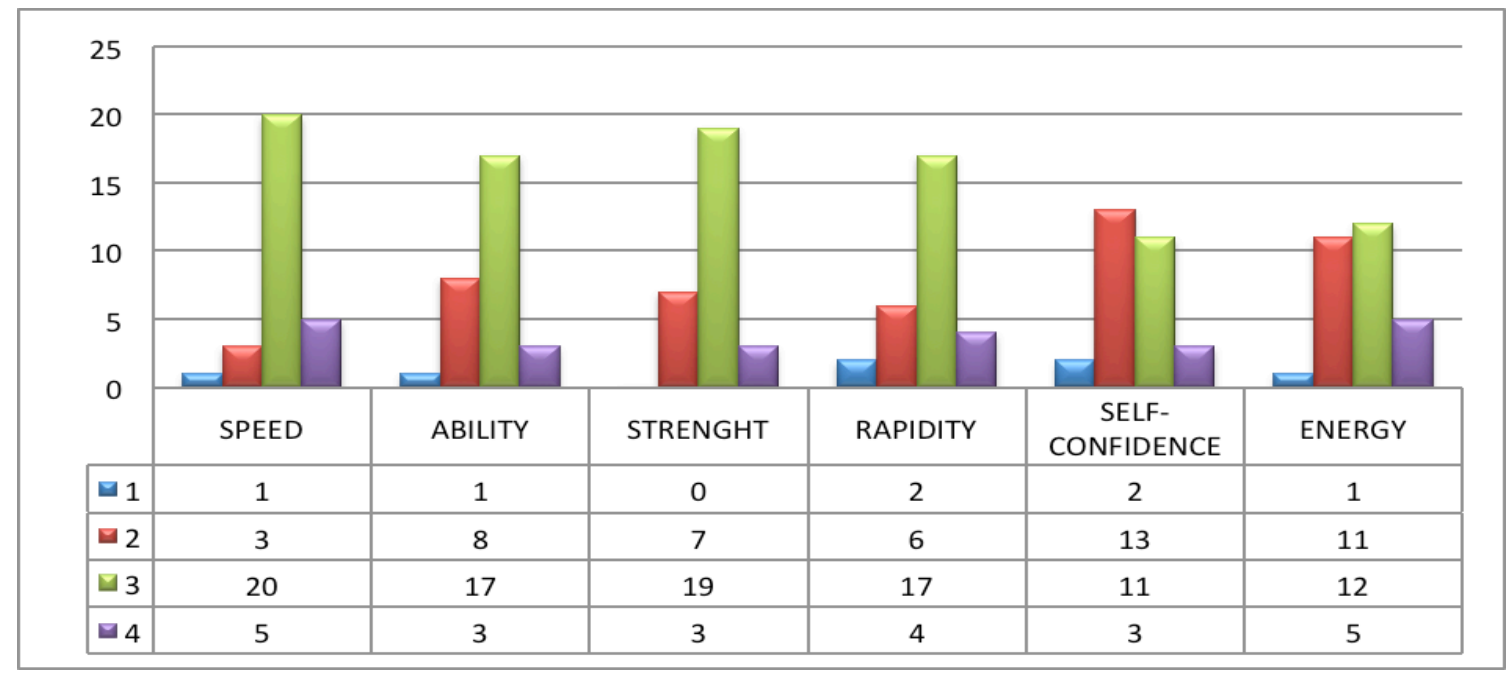

Figure 1. Perceived Physical Ability in recreational level.

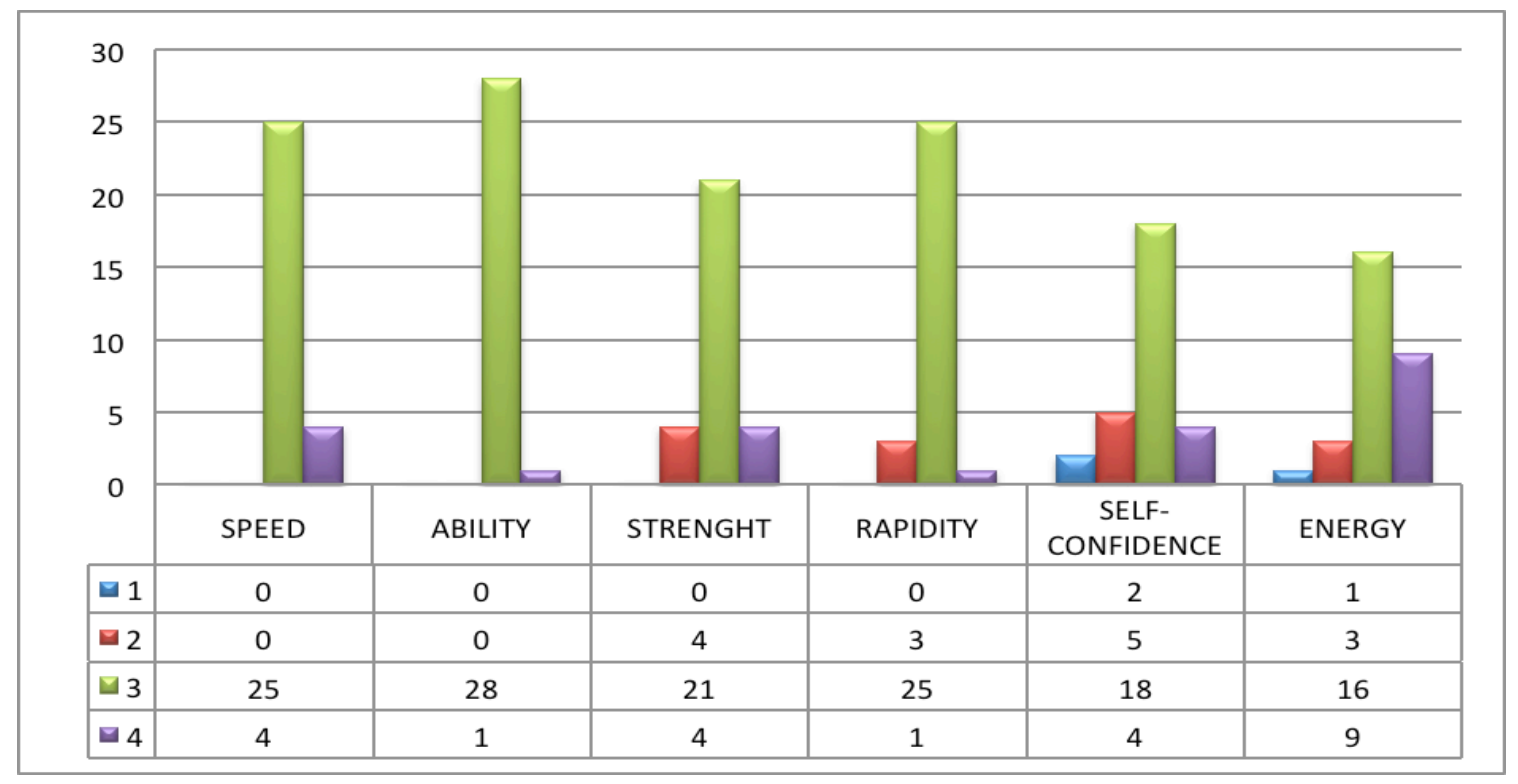

Figure 2. Perceived Physical Ability in competitive level 


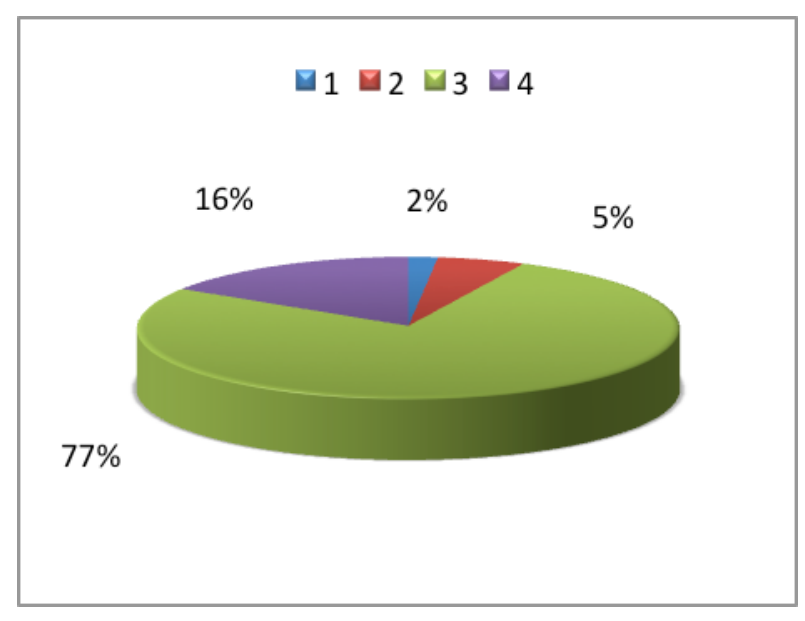

Figure 3. Speed in whole sample

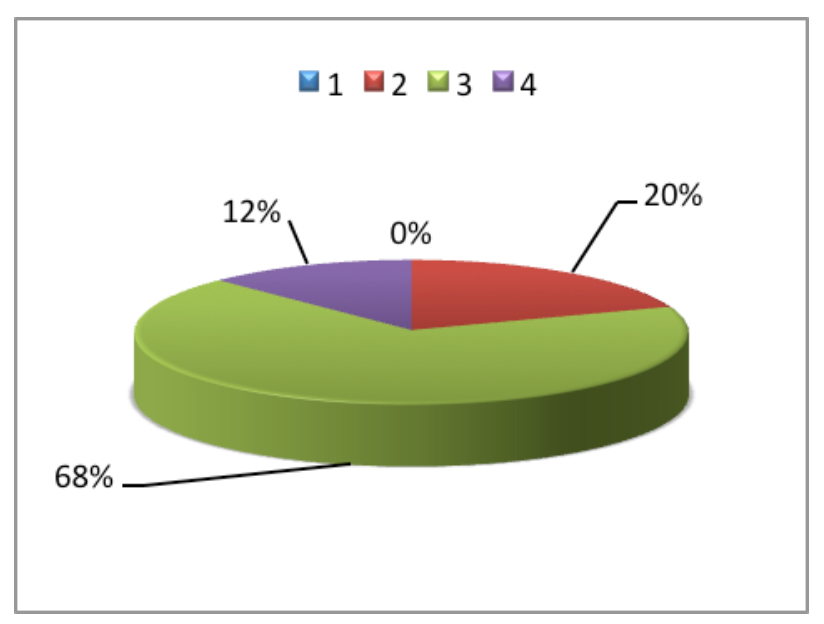

Figure 5. Strenght in whole sample

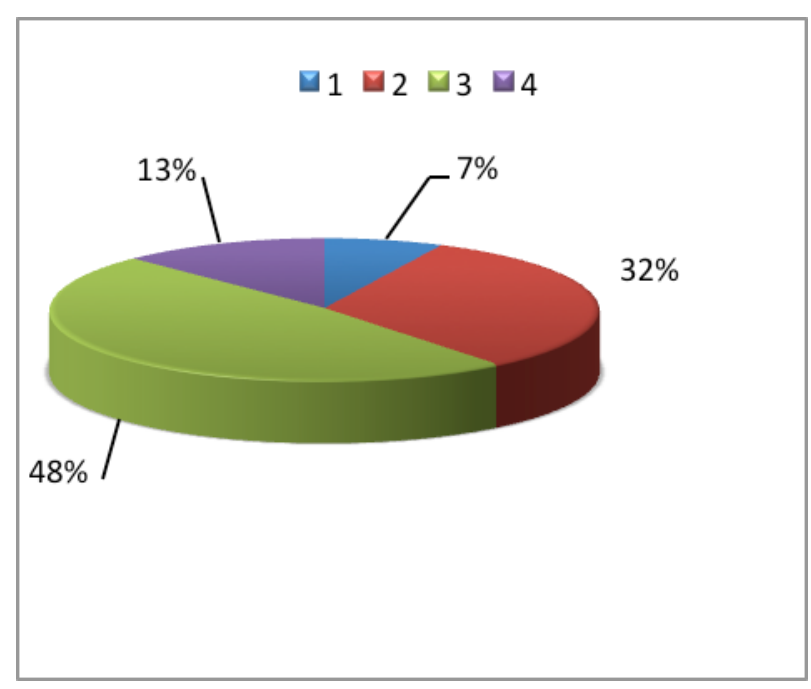

Figure 7. Self-confidence in whole sample

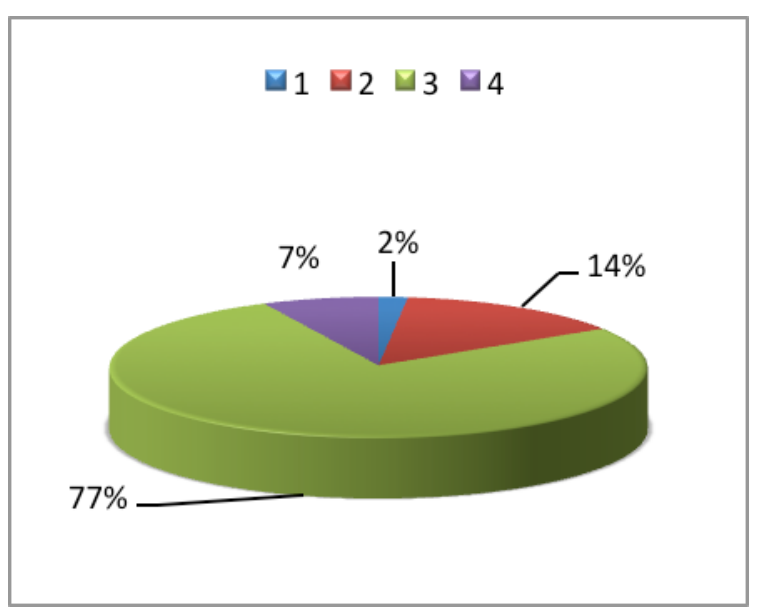

Figure 4. Ability in whole sample

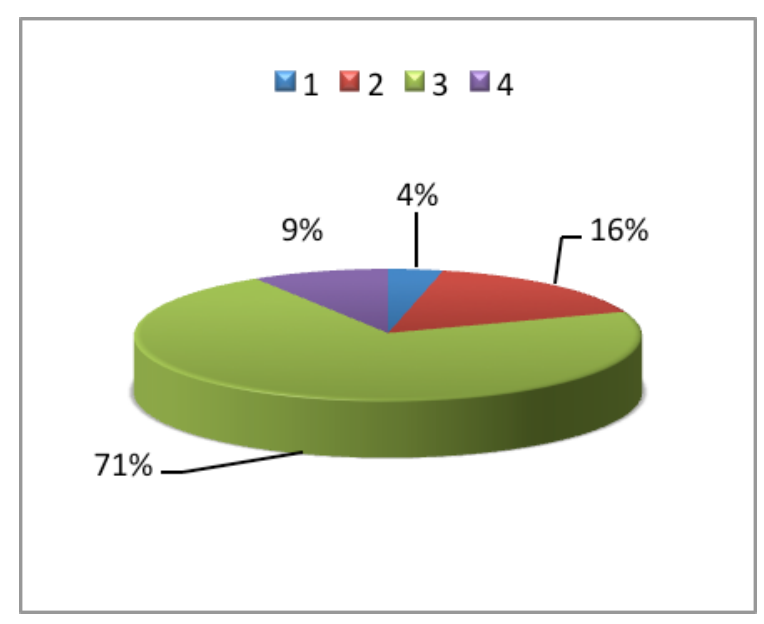

Figure 6. Rapidity in whole sample

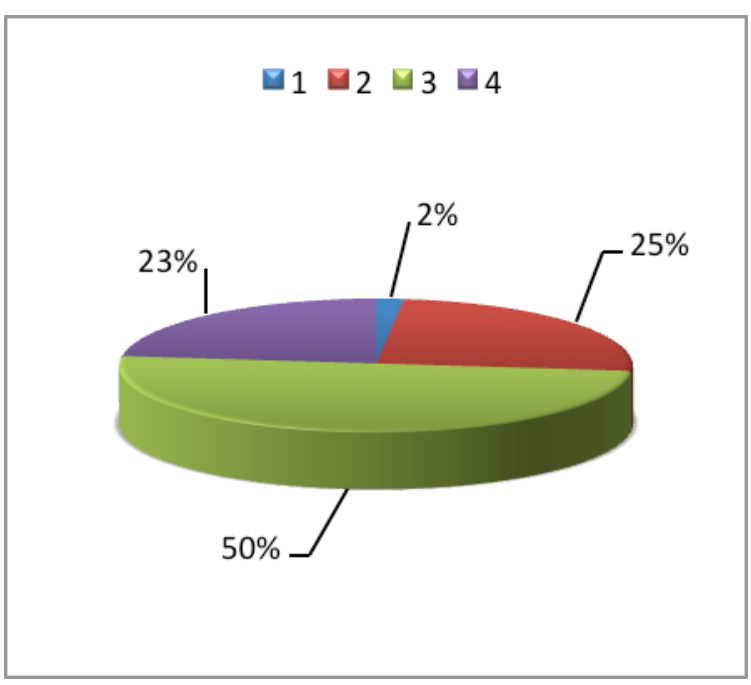

Figure 8. Energy in whole sample 


\section{DISCUSSION AND CONCLUSION}

Comparing the results of two groups (fig. 1, fig.2) is obvious a higher values in the competitive group rather than recreational group. So, observing the figure n.2 is clear that in the items speed, ability, strength and rapidity, of the competitive group, the lower range ( $1=$ light blue) and the range 2 (red) are never present or almost never. These four items highlight only the positive values.

Self-confidence and energy in both groups are lower in comparison with the other items, even though these are positive value. These results could depend on the feature of the gymnastic because the self-confidence and the energy are two particular aspect of this sport.

Many difficult are very dangerous and, at same time, require so much energy.

In both group the higher range in every items is the range 3. These results show the awareness that you can still improve to reach the best perception in the various aspects of the physical activity.

The figures that analyses the whole group of gymnasts underline that the first four items are very high, equal or greater than the $70 \%$, and the items of self-confidence and energy are about of $50 \%$.

These values confirm that probably:

- the artistic gymnastic is a sport that requires a high value of perceived self-efficacy and therefore a predisposition towards anything that is difficult and dangerous to do;

- the choice of the artistic gymnastic as sport, is in itself a selection because such a sport is not suitable for young girls who have a low perception of self- efficacy.;

- Self-confidence and energy are the aspects that in the artistic gymnastic, in particular in the competitive level are strongly stimulate and stressed.

- The artistic gymnastic, mainly at competitive level, promotes and increases the self-efficacy.

Analyzing critically the research we can state that for a better investigation it could be better to enlarge the research to a wider group and to another sport, both individual and team sports.

Future research should investigate the relationship between the Perceived Physical Ability Scale for Children and several measures of performance including physical capabilities and motor skills, as well as results of academic outcomes.

\section{REFERENCES}

1. Bandura, A. (1997). Self-efficacy: The exercise of control. New York: Freeman.

2. Bandura, A. (2000). Autoefficacia. Trento: Erickson.

3. Bandura, A. (2001). Social cognitive theory: An agentic perspective. Annual Review of Psychology, 52, pp.1-26.

4. Colella D., Morano M. (2008). A physical self-efficacy scale for children. Social behavior and personality, 36(6), pp.841-848.

5. Feltz, D.L. (1992). Understanding motivation in sport: A self-efficacy perspective. In G.C. Roberts (Ed.), Motivation in sport and exercise (pp.93-105). Champaign, IL: Human Kinetics. 
6. McAauley, E. \& Blissmer, B. (2002). Self-efficacy and attributional processes in physical activity. In T. S. Horn (Ed.), Advances in sport psychology (2nd ed., pp.185-205). Champaign, IL: Human Kinetics.

7. Multon, K.D., Brown,S.D. \& Lent, R.W. (1991). Relation of self-efficacy beliefs to academic outcomes: A meta-analytic investigation. Journal of Counseling Psycology, 38, pp.30-38. 